Santos, E.M.; Adorno, L.F.M.; Morais, P.B. Indicadores de sustentabilidade para o Ecoturismo como subsídio à implantação de Estrada - Parque no Jalapão (TO). Revista Brasileira de Ecoturismo, São Paulo, v.3, n.2, 2010, pp.249-272.

\title{
Indicadores de sustentabilidade para o Ecoturismo como subsí- dio à implantação de Estrada - Parque no Jalapão (TO)
}

\section{Eliane Marques dos Santos, Lúcio Flavo Marini Adorno, Paula Benevides de Morais}

\section{RESUMO}

Este estudo discute a temática estrada-parque para a região do Jalapão (TO), a partir da rodovia TO 030 (que liga os municípios de Novo Acordo - TO e São Félix do TO), com o objetivo de apresentar indicadores de sustentabilidade para o ecoturismo na implantação de estradas-parque nesta região. Utilizou-se um roteiro para a definição de indicadores de sustentabilidade por meio de revisão de literatura, visita a campo, avaliação através de percepção ambiental, visita técnica a estradas-parque do Mato Grosso, consulta a especialistas e elaboração da matriz de indicadores. Foram encontrados vinte e oito indicadores para as dimensões ambiental, social, espacial e econômica. Os mesmos foram classificados em quantitativos (36\%) e qualitativos (64\%), estes se apresentam em prevalência devido aos fatores relacionados à metodologia de percepção ambiental utilizada neste estudo, às características ambientais da região (principalmente os elementos da paisagem), aos elementos sociais (moradores e visitantes) e às dimensões de sustentabilidade a serem atendidas. A implantação de estradaparque na região do Jalapão pode ser uma alternativa viável para auxiliar no ordenamento territorial e no manejo da mesma, desde que sejam atendidos os critérios para a sua implantação.

PALAVRAS-CHAVE: Indicadores de Sustentabilidade, Ecoturismo, Estrada-Parque .

\section{Sustainable ecotourism indicators as subsidies to implement Park Roads in Jalapão (TO), Brazil.}

\section{ABSTRACT}

This study addresses the theme of park roads in Jalapão (TO), particularly the highway 030 (which connects the cities of Novo Acordo - TO and São Félix do TO), with the objective of presenting sustainable ecotourism indicators for implementation of park roads in this region. A guide-book was used for the definition of sustainable indicators, obtained through literature review, field trips, environmental perception assessments, technical trip to park roads in Mato Grosso (MT), and direct collaboration with specialists. We set an indicator matrix composed of twenty eight indicators, which were related to environmental, social and economic dimensions, and classified as quantitative (36\%) or qualitative (64\%). These indicators were chosen due to the methodology used here to assess environmental perception, regional environmental features (especially landscape attributes), social components (resident people and visitors), in addition to regional sustainable needs. The implementation of park roads in Jalapão can be a feasible solution helping territorial planning and management, but required criteria for such implementation must be systematically followed.

KEYWORDS: Sustainable Indicators, Ecotourism, Park Road. . 
Indicadores de sustentabilidade para o Ecoturismo como subsídio à implantação de Estrada - Parque no Jalapão (TO).

\section{Introdução}

Diante dos problemas vivenciados atualmente em relação à destruição dos recursos naturais, um dos segmentos do turismo que tem demonstrado maior crescimento é o ecoturismo. Pois, se diferencia das demais atividades na natureza devido à aplicação de princípios e valores éticos, o comportamento do turista, o conceito de sustentabilidade com desenvolvimento e o aspecto educacional (KINKER, 2002).

Sendo que o Brasil ocupa posição privilegiada, pois possui recursos naturais para atender à crescente demanda de turistas que buscam viagens em contato com a natureza (RUSCHMANN CONSULTORES, 2002).

Quanto às áreas em que se realiza o ecoturismo, tanto pode ser em propriedades privadas ou públicas, mas em quase todos os casos se encontram protegidas (MOLINA, 2001) na forma de unidades de conservação de proteção integral. O que prevalece é o desafio da sustentabilidade da atividade turística em áreas naturais protegidas, de forma que aconteça a conservação dos recursos e o desenvolvimento de comunidades locais.

A sustentabilidade não é um estado fixo de harmonia, é um conceito dinâmico que engloba um processo de mudança, e precisa levar em conta no seu planejamento de desenvolvimento, as dimensões: social, econômica, ecológica, espacial e cultural (SACHS, 1993). A sustentabilidade é determinada por um conjunto de fatores (econômicos, sociais, ambientais, entre outros) que devem ser contemplados. Dessa forma, ao se avaliar a sustentabilidade, deve-se usar sempre um conjunto de indicadores (MARZALL; ALMEIDA, 2000).

$O$ uso de indicadores de sustentabilidade para o ecoturismo nesta pesquisa deve-se ao fato de que um conjunto de indicadores adequadamente estabelecidos é uma das melhores técnicas para se acompanhar todas as fases de um planejamento ecoturístico, pois possibilita avaliar as condições de produção e consumo (do ecoturismo) atuais e acompanhar, ao longo do tempo, a evolução rumo à sustentabilidade (FILETTO, 2007).

Neste estudo entende-se que indicadores são parâmetros selecionados, considerados isoladamente ou combinados entre si, usados para avaliar determinadas condições dos sistemas em uma dada escala e são fundamentais para monitorar o desenvolvimento do turismo, as políticas públicas e suas propostas (PUPPIM DE OLIVEIRA, 2003).

Considerando que as Unidades de Conservação (UC) podem ser utilizadas como destinos turísticos, estas são implantadas com diferentes níveis de restrição quanto ao uso direto ou indireto dos recursos naturais e mesmo sócio-culturais. Deste modo, são definidas categorias de manejo para nortear os objetivos da conservação e formas de uso da área em questão.

Assim, uma das categorias de UC que tem sido implantada no Brasil sem respaldo legal, é a estrada-parque, o que pode resultar em uma estratégia não profícua para 
conservação dos recursos naturais e para a promoção do desenvolvimento sustentável na região em que se inserem. Todavia, as estradas-parque, são sempre impactantes, embora possam trazer benefícios se manejadas corretamente, assim como qualquer outra área protegida, podem também servir de instrumento de manipulação por grupos de poder, privados ou do governo (SORIANO, 2006).

Dentre os autores brasileiros consultados, consideramos neste trabalho o conceito de Estradas-parque como:

\begin{abstract}
"Unidade de conservação de grande beleza cênica, cujo formato e dimensões são definidos pela percepção das paisagens naturais e culturais a serem protegidas, a partir de uma rota principal, a estrada, e que se destina a recreação e ao lazer ao longo desta, e também como forma de promover a integração homem-natureza e o desenvolvimento sustentável da região de sua influência" (SORIANO, 2006, p.32).
\end{abstract}

Para o estado do Tocantins a discussão sobre estrada-parque teve início com o Plano de Desenvolvimento do Ecoturismo da Região do Jalapão, um diagnóstico do Programa de Desenvolvimento Ecoturístico da Amazônia Legal - PROECOTUR elaborado por Ruschmann Consultores (2002). Neste trabalho é proposto para as rodovias TO 030 (que liga Novo Acordo a São Félix do TO) e TO 225 (que liga Ponte Alta a Mateiros - TO), que levam aos principais atrativos do Jalapão, a categoria de estrada cênica pela paisagem existente no percurso.

Apesar do grande potencial ecoturístico da região apontado por Ruschmann Consultores (2002), deve ser considerado que a mesma vem sofrendo uma crescente pressão antrópica, que coloca em risco não apenas os sítios turísticos, como também o patrimônio natural, considerando ainda a escassez de estudos científicos sobre a região que abordem a questão da sustentabilidade como uma ferramenta de conservação ambiental dos roteiros (SENNA, 2008).

Baseado nestes fatores, este estudo escolheu a Rodovia TO 030 como foco de análise deste estudo para gerar a discussão de estrada-parque, por esta via possuir elementos da paisagem como potencial cênico e elementos sociais, as comunidades inseridas. Outros elementos analisados foram: o interesse do Governo Estadual na implantação de estrada-parque nesta rodovia e a crescente visitação turística nos atrativos que se encontram próximos a esta Rodovia, que é uma das estradas que levam ao Jalapão. Esta rodovia possui passivos ambientais gerados pela implantação da estrada e uso inadequado da faixa de domínio, entre outros, e em decorrência disto a degradação da paisagem. Considerando tais fatores, ressalta-se aqui a necessidade de conservação desta área, que pode ser utilizada para atividades de ecoturismo como estratégia para a conservação dos recursos naturais e para o desenvolvimento sustentável da região. 
Indicadores de sustentabilidade para o Ecoturismo como subsídio à implantação de Estrada - Parque no Jalapão (TO).

\section{Objetivos}

\section{Geral:}

Apresentar indicadores de sustentabilidade para o ecoturismo para a implantação de estrada-parque no Jalapão - TO.

\section{Específicos:}

- Estudo da paisagem a partir da caracterização das fitofisionomias;

- Identificar quais as práticas turísticas da área estudada;

- Identificar a percepção dos envolvidos sobre a conservação ambiental da área estudada e a perspectiva de sustentabilidade na implantação de estrada-parque no Jalapão.

\section{Metodologia}

A área estudada da rodovia estadual TO - 030 compreende uma extensão de 97Km, a partir do Rio Vermelho, onde se inicia a APA do Jalapão, no município de Novo Acordo até a sede do município de São Félix, conforme Figura 01.

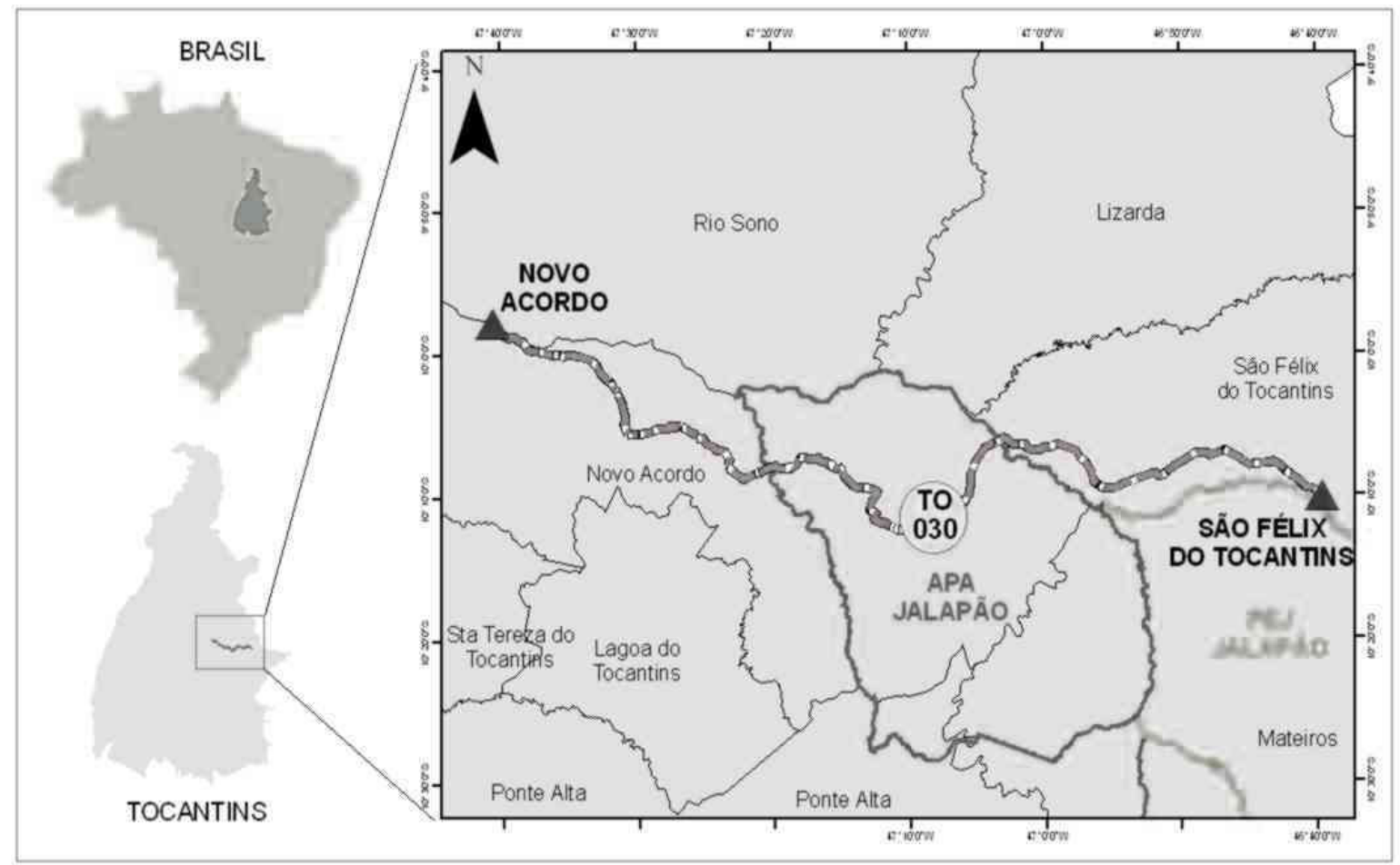

Figura 01 - Área estudada. 
O processo de seleção dos indicadores de sustentabilidade para avaliar a implantação de estrada parque no Jalapão - TO, seguiu como critérios: as características da área de estudo, a eficiência e eficácia para refletir a realidade estudada, ser seguro e estável, ser compatível com outros sistemas, responder a questão da pesquisa.

A seleção dos indicadores seguiu sete fases, descritas a seguir:

1) revisão de literatura: foram selecionados indicadores relacionados ao tema o que permitiu a definição de um conjunto de indicadores que subsidiaram as demais etapas da pesquisa, baseando-se nos trabalhos de Araújo (2001), Soriano (2006), OMT (2005), FUNBIO (2007) e Filetto (2007).

2) visitas ao Jalapão: nas saídas de campo realizadas no período de fevereiro a setembro de 2008 foi possível obter mais informações técnicas sobre a região através da caracterização da vegetação, identificação das práticas turísticas do entorno, identificação da percepção dos envolvidos sobre a conservação ambiental do roteiro e a contextualização dos indicadores obtidos na fase anterior. Nesta etapa foi confeccionado um mapa com 21 pontos de coleta de dados selecionados aleatoriamente a partir de informações da Base Cartográfica Digital Contínua (BCDC) - Geo -Tocantins (SEPLAN, 2002), para a identificação das fitofisionomias em campo, segundo FILGUEIRAS et al. (1994), com o objetivo de caracterizar a paisagem da rodovia TO 030.

Nesta etapa foi identificada a percepção dos envolvidos baseado no modelo conceitual de Whyte (1977), sendo que neste estudo utilizou-se a forma perguntando para que sejam obtidas informações sobre a percepção ambiental dos turistas (50 sujeitos) e moradores locais (18 sujeitos). Foram utilizados questionários com questões abertas e fechadas para que minimizem a interferência nas respostas e maximizem a opinião dos sujeitos envolvidos na pesquisa.

Para identificar quais as práticas turísticas do entorno foram entrevistadas seis pessoas ligadas diretamente com o turismo na região e que possuíam informações sobre seu o início e desenvolvimento.

3) Avaliação dos indicadores selecionados através da percepção ambiental: A partir da identificação da percepção dos envolvidos e dos dados obtidos nas fases anteriores, foi elaborada a lista de possíveis indicadores que foram submetidos à avaliação pelos moradores locais e turistas através da percepção ambiental, nos meses de fevereiro e julho de 2008.

4) visita técnica a estradas-parque do Mato Grosso: nesta fase, realizada em junho de 2008, foi verificado in loco a implantação de duas estradas-parque (EP) sendo levantada informações através de entrevistas com atores envolvidos (guias, moradores, órgão gestor e turista). Esta etapa teve como objetivos conhecer como se dá o 
Indicadores de sustentabilidade para o Ecoturismo como subsídio à implantação de Estrada - Parque no Jalapão (TO).

processo de gestão das EP e estabelecer uma análise crítica com os indicadores estabelecidos nas fases anteriores.

5) Elaboração de uma matriz contendo os indicadores selecionados no estudo: Foram analisados os dados obtidos nas fases anteriores e estabelecida uma matriz com 28 indicadores relacionando às características ambientais da área estudada com as dimensões de sustentabilidade propostas por Sachs (1993) e a caracterização dos indicadores como quantitativos e qualitativos de acordo com Machado (1997). Os indicadores propostos neste estudo são resultados de estudo teórico, uma base técnica realizada a partir do trabalho de campo e uma base perceptiva fundamentada na percepção dos moradores locais.

6) consulta a especialistas: nesta fase a matriz elaborada foi submetida à análise de profissionais que pesquisaram a temática estrada Parque, indicadores ou que atuam na gestão das mesmas, aqui denominados de especialistas. Um grupo de seis especialistas teve a oportunidade de revisar a lista dos indicadores. Levou-se em consideração na seleção dos especialistas dois grupos, o primeiro de profissionais do estado que conhecem e já pesquisaram na região e o segundo para aqueles que conhecem a temática em estudo, mas não conhece a região, de forma equilibradas sendo $50 \%$ o percentual para cada grupo.

7) matriz final de indicadores: após a análise das considerações emitidas pelos especialistas, foi confeccionada a matriz final dos indicadores.

\section{Resultados e discussão}

Os indicadores estão apresentados em uma matriz e estão classificados em quantitativos (36\%) e qualitativos (64\%), estes se apresentam em prevalência devido aos fatores relacionados à metodologia de percepção ambiental utilizada neste estudo, às características ambientais da região (principalmente os elementos da paisagem), aos elementos sociais (moradores e visitantes), à conservação ambiental e às dimensões de sustentabilidade a serem atendidas.

A verificação do indicador se apresenta através da presença ou ausência do mesmo (sim/não) ou questionário para os indicadores qualitativos, e porcentagem para os indicadores quantitativos.

As condições mínimas para a realização do monitoramento dos indicadores propostos neste estudo, apresentados na tabela 01, são as realizações de estudos periódicos na área de implantação, fiscalização por parte dos órgãos responsáveis, articulação com a comunidade local, estabelecimento de normas e regras propostas na matriz, destinação de recursos financeiros, entre outros. Sendo que os responsáveis por tal monitoramento devem ser o órgão ambiental (NATURATINS) e órgão responsável pelas estradas (DERTINS), de forma que estes estabeleçam um trabalho de parceria. Cabendo a outras instâncias de governança colaborar neste processo, como os governos municipais. 
Santos, E.M.; Adorno, L.F.M.; Morais, P.B.

\begin{tabular}{|c|c|}
\hline $\begin{array}{l}\text { Dirnensĩes da } \\
\text { sustentabilida- } \\
\text { de }\end{array}$ & Indicadores \\
\hline \multirow[t]{13}{*}{ I - Ambiental } & $\begin{array}{l}1 \text { - Existência de estudo sobre a biodiversidade da área da estrada- } \\
\text { parque (EP) (sim/nắo). }\end{array}$ \\
\hline & $\begin{array}{l}2 \text { - Perda da biodiversidade (sim/nẵo) e em que porcentagem por } \\
\text { período. }\end{array}$ \\
\hline & 3 - Paisagem atrativa ao ecoturismo (sim/nâo). \\
\hline & 4 - Conservaçẫo da paisagem nativa (\% de área). \\
\hline & 5 - Suporte legal da EP implantado (sim/năo) \\
\hline & G - Infra-estrutura para estrada-parque implantada (sim/nấo). \\
\hline & $\begin{array}{l}7 \text { - Existência de um Plano de uso ecoturístico da EP implantado com } \\
\text { a participaçấo pública na elaboraçẫo (sim/nấo) }\end{array}$ \\
\hline & 8 - Controle e limitaçẫo do impacto ambiental do ecoturismo (sim/nẫo) \\
\hline & $\begin{array}{l}\text { 9 - Capacidade de carga dos atrativos estabelecida e monitorada } \\
\text { (sim/năo) }\end{array}$ \\
\hline & $\begin{array}{l}10 \text { - Gestẫo integrada das Unidades de Conservaçắo do Jalapắo } \\
\text { (siminẫo) }\end{array}$ \\
\hline & 11 - Número de focos de queimadas (\%) \\
\hline & 12 - Ma nutenção freqüente da rodovia (sim/não) \\
\hline & 13 - Passivos ambientais recuperados. \\
\hline \multirow[t]{6}{*}{ II - Social } & $\begin{array}{l}14 \text { - Participação comunitária na gestắo da estrada-parque e nas } \\
\text { atividades de ecoturismo (sim/nấo) }\end{array}$ \\
\hline & $\begin{array}{l}15 \text { - Bem-estar das comunidades receptoras do ecoturismo } \\
\text { (questionário) }\end{array}$ \\
\hline & 16-Satisfação dos ecoturistas e visitantes (questionário). \\
\hline & $\begin{array}{l}17 \text { - Atividades alternativas para o desenvolvimento local identificadas } \\
\text { e implantadas (sim/năo) }\end{array}$ \\
\hline & $\begin{array}{l}18 \text { - Existência de organizaçấo entre os atores locais para } \\
\text { oferecimento de produtos. }\end{array}$ \\
\hline & $\begin{array}{l}\text { 19- Porcentagem de atendimento das demandas locais por serviças } \\
\text { públicos. }\end{array}$ \\
\hline
\end{tabular}


Indicadores de sustentabilidade para o Ecoturismo como subsídio à implantação de Estrada - Parque no Jalapão (TO).

\begin{tabular}{|c|c|}
\hline \multicolumn{2}{|c|}{ Continuaçẵo da tabela 01} \\
\hline \multirow[t]{2}{*}{ III - Cultural } & 20 - Conservaçắ do patrimônio cultural (questionário). \\
\hline & $\begin{array}{l}21 \text { - Atividades de interpretação e educaçẵ ambiental } \\
\text { desenvolvidas (sim/nẫo) }\end{array}$ \\
\hline \multirow[t]{3}{*}{ W - Espacial } & $\begin{array}{l}\text { 22-Controle do número de visitantes em relaçăo ao número de } \\
\text { moradores locais (sim/nâo). }\end{array}$ \\
\hline & $\begin{array}{l}23 \text { - Especulação imobiliária e a ecoturismo elevam preços de } \\
\text { moradias e de produtos básicos para a comunidade local (sim/năo). }\end{array}$ \\
\hline & 24 - Porcentagem de permanência dos moradores da zona rural. \\
\hline \multirow[t]{4}{*}{ V - Econômica } & $\begin{array}{l}25 \text { - Porcentagem de recursos arrecadados por meio de taxas } \\
\text { turisticas e destinaçắo destas para a EP (sim/nẫo). }\end{array}$ \\
\hline & $\begin{array}{l}26 \text { - Porcentagem de contribuiçấo do ecoturismo para a economia } \\
\text { local. }\end{array}$ \\
\hline & $\begin{array}{l}27 \text { - Porcentagem de oferecimento e consumo de produtos locais } \\
\text { pelo ecoturismo. }\end{array}$ \\
\hline & $\begin{array}{l}28 \text { - Porcentagem de aumento no desenvolvimento econômico da } \\
\text { populaçắo local. }\end{array}$ \\
\hline
\end{tabular}

Fonte: Dados da pesquisa e revisä̃o bibliográfica.

A seguir, estão discutidos os indicadores a partir dos dados obtidos neste estudo e do aporte teórico utilizado.

I - Dimensão Ambiental: refere-se à manutenção da capacidade de sustentação dos ecossistemas, o que implica na capacidade de absorção e recomposição dos ecossistemas, em face das interferências antrópicas (SILVA, 2006).

1 - Existência de estudo sobre a biodiversidade da área da estrada - parque (sim/ não).

Este é um indicador qualitativo que aponta a necessidade de um levantamento da fauna e da flora que constituem as paisagens da área em que seja implantada uma estrada-parque (EP), para subsidiar ações e políticas de conservação e preservação 
da biodiversidade. Pois, as fitofisionomias identificadas neste estudo ao longo da Rodovia TO 030 mostram a diversidade de paisagens da biodiversidade florística encontradas na área, com espécies nativas de grande importância para o bioma cerrado. A variedade de espécies evidencia o valor biológico da região.

2 - Perda da biodiversidade (sim/não) e em que porcentagem por período.

A partir do estudo sobre a biodiversidade da área, haverá um estado inicial teórico, ou seja, um mapeamento que servirá de base para se comparar a evolução da integridade da biodiversidade da área. Podendo ser estabelecido através de mapeamentos periódicos, um percentual de manutenção da biodiversidade. Este indicador é aqui considerado quali-quantitativo e poderá ser mensurado a partir de estudos periódicos.

Uma vez que foram revelados pelos moradores entrevistados do entorno da rodovia TO 030, fatos sobre a diminuição desta biodiversidade. Estes apontaram que a caça está acabando, numa fala foi apontada à preocupação com a sustentabilidade deste recurso, "meus netos não vão conhecer mais as caças, hoje já é difícil ver" (proprietário 10, 14 anos de moradia). Como também em relação à flora, "na beira da estrada encontra madeira e dependendo da quantidade tem que preservar senão é usado para cerca" (proprietário 40).

\section{3 - Paisagem atrativa ao ecoturismo (sim/não).}

É um indicador perceptivo (qualitativo) que informa as belezas existentes no roteiro do percurso da estrada e que podem ser consideradas atrativas aos ecoturistas e visitantes, como também aos moradores locais.

A paisagem da área estudada é constituída por um relevo plano a suaveondulado, com solos profundos e arenosos (neossolo quartzarênico) (SEPLAN, 2003) e fitofisionomias do cerrado entrecortada por rios e córregos.

Para os turistas pesquisados os atrativos da Rodovia TO 030 que chamam à atenção pela beleza são a Serra da Catedral (40\%), o Rio Novo (18\%) e o Morro da Cilésia (14\%). Na figura 49 é possível verificar turistas observando a paisagem.

Enquanto para os moradores das propriedades rurais ao longo da via, o lugar que lhes chamam à atenção pela beleza é a Serra da Catedral $(54,5 \% \%)$ e a Serra do Gorgulho $(45,4 \%)$, respostas que podem ter sido influenciadas pela percepção dos turistas como já foi discutido no capítulo de Percepção Ambiental. E a maioria não demonstrou sentimentos bucólicos voltados para a contemplação ou admiração da paisagem.

Em relação à vegetação, os dados apontaram que a maioria dos turistas preferiu as veredas $(26 \%)$ e o cerrado ralo rupestre $(24 \%)$, sendo que estes não expressaram em suas falas nenhum sinal de admiração por este elemento da paisagem, o que pode indicar que eles a percebem por um filtro de visitante com pouca interação. Para os moradores a relação com a vegetação consiste em sua importância para os recur- 
Indicadores de sustentabilidade para o Ecoturismo como subsídio à implantação de Estrada - Parque no Jalapão (TO).

sos hídricos, pois foi constatado maior cuidado e preocupação com as matas ciliares e matas de galerias por estarem próximas aos rios e córregos. Além do uso medicinal e alimentício. O que demonstra uma topofilia direcionada para a sobrevivência.

4 - Conservação da paisagem nativa (\% de área).

Este é um indicador qualitativo (perceptivo) interdependente dos demais indicadores para que seja verificável, pois a paisagem conservada depende da implementação de ações públicas para a preservação e proteção da paisagem da ação do homem e da minimização dos impactos ambientais existentes, tais como, desmatamentos, áreas de empréstimos, lixo, queimadas, passivos ambientais e outros. Desta forma, a conservação da paisagem de uma EP é um dos objetivos do seu manejo.

Foram verificados alguns problemas ambientais associados à rodovia TO 030 , relacionados principalmente aos passivos ambientais gerados pela construção da mesma e que não foram recuperados até a data do presente estudo. De acordo com César (2008), foram levantados 142 passivos ambientais para esta área, sendo que a maioria $(55 \%)$ relacionada a tipos de erosões. Dos passivos identificados, ressaltamse os relacionados ao uso inadequado da faixa de domínio para a construção de empreendimento turístico, implantação da rede elétrica (poluição visual), desmatamento, entre outros, que comprometem os espaços cênicos da rodovia na perspectiva da conservação da paisagem e do ecoturismo.

5 - Suporte legal da estrada-parque (EP) implantado (sim/não).

È um indicador qualitativo que se refere à implantação legal da EP. O Estado do Tocantins é um dos três estados brasileiros que possui esta categoria prevista no SEUC. Deste modo, o SEUC estabelece uma base conceitual legal mínima para subsidiar a formulação da lei ou decreto de criação específico para uma estrada-parque, em âmbito municipal e estadual. Nesta estratégia que subsidia a criação de EP deve ser considerado o aspecto de que além da promulgação de uma lei ou decreto, estes devem determinar os objetivos de manejo, a infra-estrutura e formas de gestão da EP (SORIANO, 2006).

6 - Infra-estrutura para estrada-parque implantada (sim/não).

É um indicador quali-quantitativo que apresenta a importância da implantação da estrutura de uma EP e discute a infra-estrutura para o ecoturismo na via TO 030.

Além da estrutura necessária para a implantação de EP, o ecoturismo requer uma infra-estrutura básica de visitação. Sendo que a maior parte desta, pode estar localizada nas comunidades do entorno, estimulando assim seu desenvolvimento (KINKER, 2002). Sendo assim, atualmente, no percurso da Rodovia TO 030 do Jalapão, após $72 \mathrm{Km}$ de estrada sem pavimentação é que pode ser encontrada uma lanchonete, área de camping e mini-mercado no comercial Morro Vermelho.

A consolidação de áreas produtoras tende por demandar em melhorias na infra-estrutura viária existente na região do Jalapão e em especial na rodovia TO-255 e 
TO -030 que interligam os municípios tocantinenses de Ponte Alta e Mateiros ao Estado da Bahia (TO-255 /TO 247) e Novo Acordo - São Félix do Tocantins ao Estado do Maranhão (TO- 030) (CARNEIRO, 2008). Esta realidade compromete a implantação de estrada - parque em rodovias, uma vez que nesta categoria de UC, embora de uso sustentável seja proibido este uso, como estratégia de manejo da área.

Considera-se ainda, que a Rodovia TO 030 está situada entre os dois municípios de Novo Acordo e São Félix, e estes possuem uma infra-estrutura insuficiente para o recebimento do ecoturismo conforme discutido anteriormente no capítulo de Uso turístico da rodovia TO 030 e sua relação com o Pólo Ecoturístico do Jalapão.

7 - Existência de um Plano de uso ecoturístico implantado com a participação pública (sim/não).

Constatou-se neste estudo a ausência de um Plano de uso ecoturístico para a região estudada. Sendo assim, este indicador quantitativo e perceptivo aponta a necessidade de elaboração de um plano de uso ecoturístico do Jalapão que tenha a participação pública, para que haja a ordenação e controle do lugar de destino. O mesmo deve atender as premissas da legislação e ter supervisão na sua aplicação para disciplinar o processo de ocupação e assegurar a sustentabilidade dos recursos naturais. Este plano tornar-se-á um subsídio à administração da estrada-parque e seu faixa limite no que se refere à visitação da área. Poderão ser discutidas neste as estratégias do uso ecoturístico relacionadas à cobrança e administração de taxas, roteiro de percurso, operadoras de ecoturismo, participação comunitária, entre outros.

8 - Controle e limitação do impacto ambiental do ecoturismo (sim/não).

No estudo realizado por Ferreira, Reis e Adorno, (2007) foram constatados alguns dos impactos ambientais gerados pelo turismo no Jalapão, sendo assim, este indicador qualitativo refere-se à necessidade de implantação nos destinos turísticos de: sistema de tratamento de água, existência de serviços de coleta de lixo, gestão de resíduos sólidos, controle do volume de resíduos produzidos nos destinos (atrativos) por ano e manutenção de uma imagem de limpeza nos locais (OMT, 2005).

9 - Capacidade de carga dos atrativos estabelecida e monitorada (sim/não).

Este indicador quantitativo e perceptivo aponta a importância de definição e controle da capacidade de carga dos atrativos existentes no roteiro de percurso de uma estrada-parque (EP), para proposição de ações de manejo e a elaboração de um sistema de monitoramento dos atrativos como estratégia de prevenção de impactos ambientais decorrentes do potencial uso turístico.

Segundo Ferreira, Reis e Adorno, (2007) cinco atrativos turísticos do Parque Estadual do Jalapão, localidade que recebe o maior fluxo turístico na região, possuem manejo inadequado da visitação e/ou visitação acima dos limites adequados à capacidade dos atrativos. Por isso a importância de se estabelecer este indicador, capacidade de carga, para o planejamento e manejo ecoturístico de uma EP. 
Indicadores de sustentabilidade para o Ecoturismo como subsídio à implantação de Estrada - Parque no Jalapão (TO).

10 - Gestão integrada das Unidades de Conservação (UC's) do Jalapão (sim/não).

É um indicador qualitativo que apresenta a necessidade de gestão adequada dos recursos naturais promovendo ações e políticas de preservação e conservação da biodiversidade de acordo com os objetivos das categorias de UCs existentes e as UCs com recomendação de implantação. Considerando que a implantação de uma estrada-parque (EP) no Jalapão, é indispensável que haja uma inter-relação entre as UCs existentes e a EP, uma vez que esta categoria de UC seria uma zona de manejo das demais UCs.

Desta forma, este indicador foi investigado junto aos moradores do município de São Félix (zona urbana) e aos turistas, através da questão: "Considera necessária ou desnecessária a conservação da paisagem ao longo rodovia TO 030 como um tipo de unidade de conservação e por quê?" A maioria, 85\%, dos moradores e dos turistas consideram esta estratégia necessária, em suas falas destacam-se "para preservar e tornar a viagem mais agradável" (turista 49); "para manter a paisagem, evitar redes de energia e queimadas" (morador 18) e "por ser um lugar único" (morador 17). O que demonstra uma preocupação em conservar os recursos naturais existentes e uma aceitação dos entrevistados em relação a unidades de conservação.

11 - Número de focos de queimadas controlados.

Este é um indicador quantitativo e qualitativo que aponta a necessidade de controlar os focos de queimadas na região, considerando a necessidade de conservação ambiental devido à periodicidade do uso desta prática e a vocação ecoturística.

O estado do Tocantins no ano de 2008 ocupou o $5^{\circ}$ lugar no país, com 8.840 focos de queimadas. Sendo que a APA do Jalapão teve neste ano 610 focos dos 1.815 registrados para as UCs estaduais do Tocantins, ocupando o $2^{\circ}$ lugar entre as UCs. Os municípios de Novo Acordo apresentou 72 focos e de São Félix 45 focos de queimadas (INPE, 2008). Estes dados apontam a situação em relação às queimadas dos municípios em que está a rodovia TO 030 e da APA Jalapão, considerando que esta abrange ainda dois outros municípios (Ponte Alta e Mateiros).

Nos pontos de coletas amostradas para a identificação da vegetação verificouse no período de um ano, que $81 \%$ destes pontos foram queimados neste intervalo. Sendo que os dados obtidos sobre a percepção dos turistas revelam que a maioria $(60 \%)$ aponta a queimada como prejudicial ao ambiente e em suas falas há expressões de tristeza e indignação, como na fala do turista "Nossa vida, terror! Destruindo a fauna e a flora, degradante, sou contra" (turista 14) e foi observada ainda outra sensação sobre a queimada, percebida na fala do turista como "Chocante, impactante, transmite a sensação de um ambiente que não está sendo cuidado" (turista 3), sendo que a sensação de descuido pode induzir percepções e atitudes de uso predatório da região.

Foi constatado nas percepções dos moradores entrevistados que a maioria possui preocupação quanto ao uso desta prática na região, todavia a necessidade de usar o fogo como forma de manejo para o pasto e por acreditarem que o cerrado pre- 
cisa queimar para sobreviver, fazem com que as queimadas aconteçam anualmente atingindo grandes áreas e causando danos ambientais. Para o ecoturismo as queimadas prejudicam a beleza cênica e transmitem aos turistas sentimentos de tristeza para com o lugar, como demonstrado anteriormente.

\section{2 - Manutenção frequente da rodovia (sim/não).}

Este indicador que aponta como característica da via apenas o revestimento primário, pois um dos maiores problemas da pavimentação, além da fragmentação dos ecossistemas percebidos principalmente pelos danos a fauna, é o tráfego intenso e o desenvolvimento indesejável e desestruturado que a mesma traz consigo (SORIANO, 2006). Sendo que a manutenção da via deve ser periódica de forma que apresente boas condições de rodagem, ao contrário das condições atuais.

Os dados apontam que a Rodovia TO 030 para os moradores possui um significado prático, sendo uma via de acesso para atender as suas necessidades básicas de transporte, de produção e locomoção intermunicipal. Quando questionados sobre o que mudariam na estrada, afirmaram $61 \%$ que seria a implantação de pavimentação asfáltica para melhorar o acesso, uma vez que a manutenção da via não tem sido frequente para garantir boas condições de tráfego.

Quanto aos turistas entrevistados, quando questionados se as condições da via influenciaram e ou dificultaram o seu acesso e por que, a maioria dos turistas $64 \%$, respondeu afirmativamente apontando que a estrada estava em condições ruins de tráfego, como revela um turista em sua fala "Sim, as condições precárias causa desconforto, insegurança e prejuízos" (turista 10) acrescenta ainda outro turista que "se a estrada fosse melhor viria mais vezes (turista 41)".

\section{3 - Passivos ambientais recuperados (sim/não).}

Além da manutenção frequente da via, há a necessidade de recuperação dos passivos ambientais existentes na mesma e na faixa de domínio, sendo que as erosões são os passivos que se apresentam em maior quantidade, 142 foram identificados na rodovia TO 030 (CÉSAR, 2008), estes comprometem a trafegabilidade na via e a integridade da paisagem. Outros passivos ambientais também são significativos, pois, comprometem a beleza cênica e a conservação do lugar, como a poluição visual (provocadas pela instalação de redes de energia elétrica), as áreas de empréstimos ás margens da Rodovia, os resquícios de pontes de madeira e o desmatamento.

II - Dimensão Social: a ênfase é dada à presença do ser humano na ecosfera. A preocupação maior é com o bem-estar humano, a condição humana e os meios utilizados para aumentar a qualidade de vida dessa condição (BELLEN, 2007).

14- Participação comunitária na gestão da estrada-parque (EP) e nas atividades de ecoturismo (sim/não). 
Indicadores de sustentabilidade para o Ecoturismo como subsídio à implantação de Estrada - Parque no Jalapão (TO).

Este é um indicador conceitual, pois será inserido no processo quando for implantada uma estrada - parque na região, no entanto, foi selecionado como necessário a partir do estudo bibliográfico e da visita a estradas-parques já implantadas. Este indicador refere-se à participação da comunidade no conselho gestor desta categoria de UC, bem como, o interesse comunitário em participar do planejamento e da gestão do turismo para que este se desenvolva de forma sustentável. Esta organização e envolvimento da comunidade têm que ser de iniciativa do órgão responsável pela administração da EP.

15- Bem-estar das comunidades receptoras do ecoturismo (questionário).

Refere-se ao grau de satisfação da população local para com as questões do desenvolvimento, da participação, dos ganhos econômicos advindos do ecoturismo e da degradação de um modo geral (FILETTO, 2007).

De acordo com os dados da pesquisa a maioria dos moradores considera o turismo como positivo para a região, mas aponta a falta de infra-estrutura para receber o turista e os prejuízos ambientais que esta atividade tem trazido. Sendo que os proprietários de fazendas em relação aos moradores da cidade, apostam no turismo como uma alternativa para o desenvolvimento da região e possuem interesse em oferecer produtos aos turistas.

No entanto, fica claro a partir da insatisfação dos moradores que o tipo de turismo predominante na área estudada não condiz com o ecoturismo, uma vez que os moradores acreditam que pode haver mais incentivo para que esta atividade tenha mais resultados, e não tenham em sua região, turistas que "passam e deixam apenas poeira e buracos na estrada" (morador 4).

16 - Satisfação dos ecoturistas e visitantes (questionário).

Refere-se ao nível de satisfação do visitante quanto: ao lugar de destino ecoturístico, a relação qualidade de produtos e o preço, a infra-estrutura e os serviços oferecidos (OMT, 2005).

De acordo com os Indicadores propostos pela OMT (2005), a satisfação dos turistas é verificável através daqueles que retornam ao destino. Considerando tal indicador, foi perguntado aos turistas entrevistados se desejavam retornar ao Jalapão e por quê. Significativamente a maioria, 98\% afirmaram positivamente, o que corrobora com o trabalho de Dutra et al (2008). Sendo que as razões para o retorno da maioria (52\%) foram pelas belezas do lugar, o que corrobora com o estudo de Senna (2008) onde a maioria (36\%) dos turistas respondeu que a motivação de conhecer o Jalapão foi o contato com a natureza.

Quando questionados sobre quais os serviços inexistentes que consideravam interessantes de serem implantados na rodovia TO 030, e estes informaram: lanchonetes e restaurantes (22\%), melhores condições na estrada (18\%), placas informativas $(16 \%)$ e outros. O que demonstra que embora haja o desejo de retornar ao Jalapão pela maioria, estes apontam melhorias para o turismo na região. 
17 - Atividades alternativas para o desenvolvimento local identificada e implantada (sim/não).

Este indicador aponta a necessidade de um estudo detalhado para identificar as vocações ecoturísticas da região, as alternativas e programas de incentivo ao desenvolvimento local.

De acordo com dados deste estudo, atualmente a ocupação econômica da maioria dos moradores ao longo da rodovia TO 030, é a agricultura e a pecuária de subsistência, sendo que apenas dois dos onze entrevistados já oferecem produtos como lanches e refeições aos turistas, que são o Comercial Morro Vermelho e o Café do Agresto. Mas $91 \%$ dos sujeitos pesquisados, afirmaram que se tivessem condições ofereceriam algum tipo de serviço ao turista e quando questionados sobre qual serviço ofereceriam, a maioria $37 \%$, apontaram que montariam uma lanchonete, sendo que os demais serviços citados foram: turismo rural, restaurante, hotel fazenda e passeios ecoturísticos (banho de cachoeira e andar a cavalo).

Foram citados pelos entrevistados, os aspectos que os impedem de fazer tal investimento são: a ausência de estímulos dos governos, a falta de energia elétrica, de estradas em boa condição de tráfego e de divulgação. Pois, os mesmos vêem o turismo como uma oportunidade de desenvolvimento econômico regional.

Considerando os dados obtidos, este indicador versa sobre a importância do desenvolvimento regional, mas devem ser consideradas as expectativas das comunidades envolvidas, o potencial da região para o ecoturismo e demais atividades, e a necessidade de implantação de políticas que objetivem tal desenvolvimento.

18 - Existência de organização entre os atores locais para oferecimento de produtos.

Foi constatada neste estudo a ausência de organização na forma de cooperativas ou associações entre os moradores das comunidades no oferecimento de produtos aos visitantes. Pois, $90 \%$ dos moradores entrevistados, afirmou que ofereceriam produtos caso tivessem incentivos, entre eles o aumento do fluxo turístico e infraestrutura. Este indicador tem uma dependência do anterior no sentido de identificação e implantação de alternativas de renda para as comunidades, e uma vez consolidadas tais ações, é necessário que haja uma organização entre os atores locais para estes possam divulgar o ecoturismo como um todo na região e não apenas o seu próprio empreendimento.

19 - Porcentagem de atendimento das demandas locais por serviços públicos.

As demandas locais da região estudada são: coleta de lixo, abastecimento de água tratada, rede elétrica, destinação adequada e tratamento de resíduos sólidos, estrada em boas condições de tráfego, linha de transporte intermunicipal funcionando, entre outros. Estes dados devem ser considerados para o planejamento de ecoturismo na região, principalmente com atividades de educação ambiental para as comunidades. 
Indicadores de sustentabilidade para o Ecoturismo como subsídio à implantação de Estrada - Parque no Jalapão (TO).

III - Dimensão Cultural: está relacionada ao caminho da modernização sem o rompimento da identidade cultural dentro de contextos espaciais específicos (SACHS, 1986). Apesar da importância desta dimensão, os indicadores propostos não são resultados de trabalho de campo, são conceituais, selecionados a partir da bibliografia, pois, se apresentam como fatores que serão inseridos no processo quando for implantada uma estrada - parque na região.

20 - Conservação do patrimônio cultural (questionário).

A visitação turística em uma determinada região pode comprometer os hábitos e costumes das comunidades nela inseridas, sendo que a cultura guarda, de fato, certa relação com a proximidade, com o ambiente geográfico, com o local (SILVA, 2006). Desta forma, este indicador conceitual, apresenta a necessidade de ações integradas e efetivas que levem à conservação do patrimônio cultural, envolvendo as questões ambientais legislação, educação ambiental, alternativas de renda, gestão e manejo das áreas, todos estes influenciados pela cultura dos usuários.

21 - Atividades de interpretação e educação ambiental desenvolvidas (sim/não).

Este indicador perceptivo aponta a necessidade de uma educação e interpretação do patrimônio ambiental e cultural para a população local, atores sociais e visitantes.

Apesar da região do Jalapão ser denominada como um Pólo Ecoturístico, ainda não foi elaborado um Plano de uso ecoturístico que defina os objetivos e possíveis usos da região, desta maneira não há trabalhos de educação ambiental para moradores e nem visitantes que chegam aos atrativos turísticos.

Os dados deste estudo revelam alguns problemas como impactos e passivos ambientais, que apontam a necessidade de estratégias de conscientização da comunidade e visitantes quanto à importância e uso sustentável dos recursos naturais, como também, para melhor compreenderem as inter-relações ambientais e a importância de uma unidade de conservação.

Tais atividades podem ser inseridas na educação formal de ensino das comunidades, como também, a utilização de palestras informativas e capacitações para toda a comunidade. E para os ecoturistas, educação no âmbito informal, como placas interpretativas, guias capacitados e serviços de informações.

IV - Dimensão Espacial: refere-se à capacidade de suporte do planeta, ante o crescimento desenfreado da população e suas consequentes características, como ocupação irregular do espaço, migração, etc. (SACHS, 1986).

22 - Controle do número de visitantes em relação ao número de moradores locais (sim/não). 
Este indicador apresenta a necessidade do controle do número de visitantes em relação ao número de moradores locais, considerando os períodos de alta e baixa temporada. De acordo com os dados dessa pesquisa os períodos de maior visitação no Jalapão nos atrativos do município de Mateiros, são nos feriados de carnaval, semana santa, sete de setembro e no mês de julho.

De acordo com os dados dessa pesquisa os períodos de maior visitação no Jalapão nos atrativos do município de Mateiros, são nos feriados de carnaval, semana santa, sete de setembro e no mês de julho.

Os municípios do Jalapão possuem baixa densidade populacional, sendo assim, um fluxo turístico concentrado no mesmo local e data podem causar problemas às comunidades e aos recursos naturais.

Quanto aos recursos naturais, no trabalho de Ferreira, Reis e Adorno (2007) sobre 0 atrativo Cachoeira do Formiga, que deve receber no máximo oito grupos com 21 visitantes cada, ao longo do dia para que tenha sua capacidade de carga respeitada, a observação de alguns dados de fluxo obtidos durante os principais picos de visitação em 2006, indica que apenas no dia 7 de setembro o número de visitantes superou a capacidade de carga aqui sugerida. Estes dados apontam que o fluxo turístico no atrativo é superior à capacidade de carga do mesmo em períodos de alta temporada.

23 - Especulação imobiliária e o ecoturismo elevam preços de moradias e de produtos básicos para a comunidade local (sim/não).

Com o desenvolvimento do ecoturismo em algumas regiões é comum o aumento dos preços de terras e de produtos comerciais. Foi o que ocorreu com a criação do Parque Nacional Chapada Diamantina, fato que se repetiu em Chapada dos Guimarães - MT. Na região do Jalapão este ainda não é um problema porque o ecoturismo ainda não está consolidado na região como a principal atividade econômica, mas poderá vir a surgir com a implantação de uma estrada-parque.

Sendo assim, este é um indicador conceitual, pois depende da consolidação do ecoturismo na região como atividade econômica. O mesmo aborda a necessidade de controle e minimização deste impacto turístico para que não haja êxodo rural provocado pela procura de terras na região do Jalapão visando o investimento no ecoturismo. Como também, que não haja aumento dos produtos básicos para a comunidade local, devido aos valores a serem cobrados aos visitantes.

\section{4 - Porcentagem de permanência dos moradores da zona rural.}

Refere-se à necessidade de equilíbrio entre moradores na zona rural e na zona urbana de forma que não haja uma concentração maior nas cidades, o que demonstraria a satisfação dos moradores das propriedades rurais com sua ocupação econômica em permanecer em suas moradias, podendo ter ligação ou não com o ecoturismo. 
Indicadores de sustentabilidade para o Ecoturismo como subsídio à implantação de Estrada - Parque no Jalapão (TO).

Os dados apontam que a maioria (82\%) dos moradores de propriedades rurais possuem renda familiar entre 1 a 3 salários mínimos, o que demonstra um baixo poder aquisitivo e que $82 \%$ utilizam a terra para agricultura e pecuária de subsistência. Sendo que estes vêem no turismo uma alternativa de desenvolvimento, o que requer um planejamento para a implantação do ecoturismo de forma que sejam envolvidas as comunidades locais e sejam também consideradas as dimensões de sustentabilidade para o uso dos recursos naturais, procurando assim, evitar impactos negativos desta implantação.

Devem ser considerados ainda os valores afetivos dos moradores quanto ao lugar onde moram, que está relacionado com a valorização do lugar onde residem, com a terra da qual sobrevivem e com o bem-estar que o lugar lhe propicia.

V - Dimensão Econômica: abrange a alocação e distribuição eficiente dos recursos naturais dentro de uma escala apropriada, considerando a escassez dos mesmos (BELLEN, 2007).

25 - Porcentagem de recursos arrecadados por meio de taxas turísticas e destinação destas para a estrada-parque.

Este indicador verifica o volume de taxas arrecadadas com o ecoturismo e a sua destinação de acordo com a gestão da estrada-parque (EP). Algumas das possíveis taxas a serem estabelecidas numa EP são: o estabelecimento de pedágio, ingresso único para visitação aos atrativos e outros. Sendo que a administração dos recursos deve estar vinculada ao conselho gestor da EP.

Foi questionado aos turistas se pagariam alguma taxa de conservação e administração para manter uma unidade de conservação (UC) quando usadas por eles, destes apenas 12\% afirmaram que não estariam dispostos a pagar uma taxa. Embora a maioria (88\%) se disponha a pagar uma taxa, $40 \%$ destes afirmam que só pagariam se constatassem algum retorno em relação às melhorias na estrada e na conservação da natureza.

E quanto ao valor que estavam dispostos a pagar, variou entre $R \$ 5,00$ e 50,00 , tendo sugestão para ingresso único de toda a alça viária de $R \$ 150,00$.

Estes dados apontam que a maioria dos turistas possui uma boa receptividade à cobrança de taxas para visitação, mas estes apresentam certo descrédito quanto à administração deste recurso ser realizada pelo governo como revela o turista em sua fala "pagaria aos moradores locais e não para o governo" (turista 7).

26 - Porcentagem de contribuição do ecoturismo para a economia local.

Este indicador busca verificar a proporção da atividade econômica local gerada unicamente pelo ecoturismo. A contribuição financeira dos serviços oferecidos ao ecoturismo na renda familiar dos envolvidos será um indicador quantitativo e perceptivo 
para a qualidade de vida dos moradores e a sua satisfação com as atividades turísticas desenvolvidas na região.

A expectativa dos moradores das propriedades rurais ao longo da TO 030, em relação ao turismo como gerador de renda para a região é alta. A maioria, 90\%, afirmou que ofereceriam produtos caso tivessem incentivos, entre eles o aumento do fluxo turístico. Considerando a baixa renda da maioria destes moradores, o turismo seria uma forma de melhorar esta renda.

27 - Porcentagem de oferecimento e consumo dos produtos locais pelo ecoturismo.

O envolvimento da comunidade local para oferecer serviços para o ecoturismo e a venda destes produtos é um indicador importante para o ecoturismo, considerando ainda, que os ecoturistas se interessam pela cultura das comunidades e por isso buscam adquirir os produtos locais.

Atualmente no Jalapão o produto artesanal de maior interesse turístico são as peças ornamentais de capim - dourado, embora já existam outros produtos do cerrado sendo oferecidos, tais como, farinha de jatobá, doce de buriti, ornamentos de buriti e outros (ADORNO et al., 2008) estes são encontrados no município de Mateiros. O que aponta as potencialidades de geração de renda para as comunidades de outras áreas do Jalapão, como forma também de diminuir a pressão nos ambientes naturais com o uso da pecuária e da agricultura.

28 - Porcentagem de aumento no desenvolvimento econômico da população local.

É um indicador que verifica se houve aumento no desenvolvimento econômico das comunidades locais a partir do ecoturismo. Esta investigação poderá ser realizada através de pesquisa com a comunidade

A comunidade de Mumbuca no município de Mateiros no Jalapão, segundo o trabalho de Santos, et al. (2007), teve com o incremento da atividade turística, o aumento do indicador emprego e renda que cresceu $1.321,96 \%$, sendo o item com maior crescimento na composição do índice de qualidade de vida investigado neste estudo. Anteriormente a comunidade tinha um rendimento inferior a um salário mínimo, sendo que a população se estabelecia sócio-economicamente, como produtora agrícola de subsistência e a sobra vendida para aquisição de outros produtos de primeira necessidade. Este aumento deve-se ao artesanato de capim-dourado. A renda desses produtos é o principal sustento das famílias, que admitem terem aumentado seus rendimentos, especialmente nos meses de julho, agosto, dezembro e janeiro, quando aumenta o fluxo de turistas, melhorando suas condições de vida. 
Indicadores de sustentabilidade para o Ecoturismo como subsídio à implantação de Estrada - Parque no Jalapão (TO).

\section{Conclusões}

A matriz de indicadores proposta como resultado final responde aos questionamentos iniciais sobre como deve ser a implantação de estrada-parque no Jalapão.

Através dos resultados obtidos podem ser traçadas estratégias para a conservação ambiental e gestão pública, como também, o incentivo de pesquisas que viabilizem uma manutenção e gestão viária pautada na preservação ambiental.

Todavia, de acordo com Soriano (2006), o trecho estudado da Rodovia TO 030 se enquadra na categoria de Estrada - Ecológica por atravessar a APA do Jalapão e também o entorno do PEJ. Sendo assim, o que se propõe é que a estrada passe efetivamente a ser uma zona de manejo da APA do Jalapão e do PEJ atenuando os impactos negativos oriundos da implantação e funcionamento do trecho analisado.

A estrada-ecológica, segundo Soriano (2006), tem como principais objetivos de manejo a promoção da educação ambiental, recreação, turismo e lazer. Integração sociedade e unidade de conservação e conservação da paisagem cultural e natural.

Qual a melhor saída para a estrutura da Rodovia TO 030? Para tal questão, considera-se essencial que sejam solucionados os problemas relativos à ordenação do turismo na região, a implantação da infra-estrutura necessária à administração das UCs e em parceria com a comunidade seja discutida a infra-estrutura da estradaecológica. Para que não se repita a situação observada nas estradas-parque do Mato Grosso e outras do Brasil, existentes apenas nos decretos de criação, mas que não possuem ações de manejo e nem participação comunitária.

A implantação de estrada-parque (EP) no Brasil em Rodovias tem se mostrado uma estratégia ineficaz quanto aos objetivos de manejo, principalmente relacionados à estratégia de proteção da biodiversidade e da paisagem. Uma vez que a implantação de EP tem sido para a li ligação intermunicipal ou dentro de um parque, e não como destino ecoturístico, as mesmas não são aproveitadas pelo potencial cênico existente. O que na maioria dos casos não possibilita restringir o uso das vias de acordo com as necessidades de manejo de uma EP. Sendo assim, nenhuma rodovia para ser coerente com a categoria de UC, deveria ser enquadrada como EP.

Pergunta-se então, é viável a implantação de estrada-parque como unidade de conservação na região do Jalapão? Sim, pode ser uma alternativa viável para auxiliar no ordenamento territorial e no manejo da região. No entanto, para que esta proposta seja viável devem ser considerados os seguintes critérios:

- A implantação legal como uma unidade de conservação, que implica na implantação do plano de manejo e de uma infra-estrutura de administração;

- Os princípios do ecoturismo: utilizar de forma sustentável o patrimônio natural e incentivar a sua conservação, envolvendo as comunidades receptoras no processo de forma que promova o seu desenvolvimento;

- A implantação do mosaico de unidades de conservação do Jalapão para que 
a estrada-parque seja uma zona de manejo para tais UCs.

- Que haja a integração entre o órgão responsável pela manutenção da estrada (DERTINS) e pelo órgão ambiental (NATURATINS) para que o manejo da área seja coerente á proposta da categoria de EP.

- Considerar a matriz de indicadores apresentada neste estudo como uma ferramenta para a implantação e monitoramento de EP.

Os indicadores propostos neste estudo para a região do Jalapão geraram uma ferramenta a ser utilizada para a análise de projetos de EP a serem implantados, e que tenham como objetivo o uso sustentável da área através da implantação de uma categoria de unidade de conservação para o manejo e para o desenvolvimento do ecoturismo. Servindo ainda como um desmistificador de propostas de EP que não sigam os objetivos a que se propõe esta categoria.

Nesse sentido, recomendam-se estudos relacionados à aplicação dessa ferramenta em outras estradas do Jalapão, que não seja uma rodovia, para serem identificadas as áreas potenciais de implantação de estrada-parque.

\section{Referências Bibliográficas}

ARAÚJO, R. M. P. Estrada Parque Pantanal: uma ferramenta de conservação da biodiversidade Pantaneira. Dissertação de mestrado do curso de Gestão e política Ambiental, UnB, Brasília, 2001.

ADORNO et al. Relatório do NEATUS. Considerações sobre a geração de Impactos Ambientais do Rally Internacional dos Sertões na Região do Jalapão. Universidade Federal do Tocantins, NEATUS. Julho a outubro, 2006.

BELLEN, H. M. V. Indicadores de sustentabilidade: uma análise comparativa. 2. ed. Rio de Janeiro: FGV, 2007.

CARNEIRO, B. M. Implantação de vias e manejo de áreas protegidas na região do Jalapão: a Rodovia TO 110 e o seu entorno. Dissertação (Mestrado em Ciências do Ambiente) Fundação Universidade Federal do Tocantins, Palmas, 2008.

CESAR, B. R. Levantamento dos passivos ambientais da Rodovia TO 030 no trecho Novo Acordo a São Félix do Tocantins. Monografia em conclusão. Curso de Engenharia Ambiental da UFT, 2009.

DUTRA, V.C.; SENNA, M.L.G.S.; FERREIRA, M.N.; ADORNO, L.F.M. Caracterização do perfil e da qualidade da experiência dos visitantes no Parque Estadual do Jalapão, Tocantins. Caderno Virtual de Turismo, Vol. 8, N 1, 2008. 
Indicadores de sustentabilidade para o Ecoturismo como subsídio à implantação de Estrada - Parque no Jalapão (TO).

FERREIRA, M.N.; REIS, E.S.; ADORNO, L.F.M. Caracterização dos impactos do uso público no Parque Estadual do Jalapão. In: V Congresso Brasileiro de Unidades de Conservação, 2007, Foz do Iguaçu. Anais do V Congresso Brasileiro de Conservação. Curitiba: Fundação O Boticário, 2007.

FILGUEIRAS, T. S.; SILVA, P.E. N.; BROCHADO, A. L.; GUALA II, G. F. Caminhamento - um método expedito para levantamentos florísticos qualitativos. Cadernos de Geociências, v. 2, n. 4, 1994.

FILETTO, F. Desenvolvimento de indicadores de sustentabilidade para o ecoturismo em Unidade de Conservação. Tese de Doutorado. UFLA, Lavras - MG, 2007.

FUNBIO. Programa Melhores Práticas para o Ecoturismo. Dezembro, 2000. Disponível em: www.funbio.org. Acessado em 06 ago. 2007.

GALLOPIN, G. C. Environmental and sustainability indicators and the concept of situational indicators. A system approach. Environmental Modelling and Assessment. n. 1, p. 101-117, 1996.

KINKER, S. Ecoturismo e conservação da natureza em Parques Nacionais. Campinas, SP: Papirus, 2002.

MACHADO, L. M. C. P. Qualidade ambiental: indicadores quantitativos e perceptivos. In: MARTOS, H. L.; MAIA, N. B. (org.). Indicadores ambientais. Sorocaba: A. N., 1997.

MARZALL, K.; ALMEIDA, J. Indicadores de sustentabilidade para agroecossistemas: estado da arte, limites e potencialidades de uma nova ferramenta para avaliar o desenvolvimento sustentável. Cadernos de Ciência \& Tecnologia, Brasília, v.17, n.1, p.41-59, jan./abr. 2000

MOLINA, E. S. Turismo e Ecologia. Bauru, SP: EDUSC, 2001.

OMT - ORGANIZACIÓN MUNDIAL DEL TURISMO. Indicadores de desarrollo sostenible para los destinos turísticos, guía práctica. Madrid, España: Impreso por la Organización Mundial del Turismo, 2005.

PUPPIM de OLIVEIRA, J.A. Instrumentos Econômicos para Gestão Ambiental: Lições das Experiências Nacional e Internacional. Salvador: Centro de Recursos Ambientais : NEAMA, 2003.

RIBEIRO, J. F.; WALTER, B. M. T. Fitofisionomias do bioma Cerrado. In: Sano, S., Almeida, S. P. (Ed.) Cerrado: ambiente e flora. Planaltina, DF: EMBRAPA-CPAC, 1998.

RUSCHMANN CONSULTORES. Plano de Desenvolvimento do Ecoturismo da Região do Jalapão - PROECOTUR. São Paulo, 2002. 
SACHS, I. Ecodesenvolvimento: crescer sem destruir. SP. Vértice. 1986. . Estratégias de transição para o século XXI. In: BURSZTYN, M. (org.). Para pensar o desenvolvimento sustentável. São Paulo: Brasiliense, 1993.

SANTOS, E.G.; ARMOND, F.N.; NUNES, I.H.; SENNA, M.L.G.S.; PARENTE, T.; MORAES, P.B; RODRIGUES, W. Sustentabilidade e Desenvolvimento Local: A comunidade de Mumbuca e o turismo da região do Jalapão. Revista OLAM Ciência e Tecnologia. v. 7; n. 3, p. 242-261, Dezembro, 2007.

SEPLAN, Secretaria do Planejamento e Meio Ambiente. Plano de Manejo da Área de Proteção Ambiental do Jalapão - APA, 2003. Disponível em: < I www.seplan.to.gov.br>. Acesso em: 10.03.2008.

SEPLAN, Secretaria do Planejamento e Meio Ambiente. Base Cartográfica Digital Contínua - GeoTocantins. Diretoria de Zoneamento Ecológico e Econômico, Palmas, 2002.

SENNA, M. L. G. S. Percepção e representação ambiental dos guias/condutores de turismo e dos turistas do Parque Estadual do Jalapão/TO, como fator influenciador da prática ecoturística, 2008. Dissertação de mestrado em Ciências do Ambiente da Universidade Federal do Tocantins. Palmas: 2008.

SILVA, L. C. Proposta de um modelo de monitoramento e avaliação do desenvolvimento sustentável. In: SILVA, L. C. (Org.). Desenvolvimento sustentável: um modelo analítico integrado e adaptativo. Petrópolis, RJ: Vozes, 2006.

SORIANO, A. J. S. Estrada-parque: proposta para uma definição. Tese de Doutorado. Rio Claro, Unesp, 2006.

WHYTE, A. Guidelines for Fields Studies Inenviromental Perception. MAB Technical Notes \%, Paris: UNESCO, 1977.

\section{Agradecimentos}

A todos que colaboraram com este estudo.

Ao Governo do Estado do Tocantins, através da Secretaria de Ciência e Tecnologia, pela bolsa de estudos.

À Universidade Federal do Tocantins e ao Núcleo de Estudo Estratégicos e Avaliação Ambiental em Turismo Sustentável - NEATUS. 
Indicadores de sustentabilidade para o Ecoturismo como subsídio à implantação de Estrada - Parque no Jalapão (TO).

Eliane Marques dos Santos: Bióloga, mestre em Ciências do Ambiente, professora assistente do curso de Ciências Biológicas - UFT.

Email: biologa.eliane@gmail.com

Link para o currículo Lattes: http://lattes.cnpq.br/5291006759659655

Lúcio Flavo Marini Adorno: Prof. Adjunto, curso de Ciências do Ambiente - UFT. Email: drlucioflavo@uft.edu.br

Link para o currículo Lattes:http://lattes.cnpq.br/3907675985493595

Paula Benevides de Morais: Profa Adjunta, curso de Ciências do Ambiente - UFT. Email: leymoraispb@uft.edu.br

Link para o currículo Lattes: http://lattes.cnpq.br/8545749738251622

Data de submissão: 02 de novembro de 2009.

Data do aceite: 09 de abril de 2010 . 